\title{
Evaluation of the conformity of assistential practice in the maintenance of the temporary double-lumen dialysis catheter ${ }^{1}$
}

\author{
Késia Alves Gomes Rosetti² \\ Daisy Maria Rizatto Tronchin ${ }^{3}$
}

\begin{abstract}
Objective: to evaluate the conformity of the assistential practice in the maintenance of the temporary double-lumen catheter for hemodialysis, by means of the use of the process indicator, in the University Hospital of the University of São Paulo. Method: a quantitative, exploratorydescriptive and observational study. The sample was made up of 155 observations of persons with temporary double-lumen catheters, in the period March - November 2011, using the Indicator of the Maintenance of the Temporary Double Lumen Catheter for Hemodialysis. Results: the rate of general conformity of the assistential practice corresponded to 65.8\%. Of the practice's 13 components, 9 (69.2\%) attained $100 \%$ conformity. The hygienization of hands by the professionals and the use of a mask by the patients during the disconnection from the hemodialysis had the worst rates (83.9\%). Conclusion: although the actions evaluated are implemented in the unit, it is necessary to propose and apply educational strategies with the health team, as well as to institute periodical assessments, so as to raise the conformity rates, ensuring the quality of the hemodialysis services.
\end{abstract}

Descriptors: Quality of Health Care; Health Services Evaluation; Quality Indicators, Health Care; Renal Dialysis; Nursing.

\footnotetext{
${ }^{1}$ Paper extracted from master's thesis "Evaluation of maintenance indicator of temporary double-lumen catheter for hemodialysis in a university hospital" presented to Escola de Enfermagem, Universidade de São Paulo, São Paulo, SP, Brazil.

2 MSc, RN, Hospital Geral de Guarus, Campos dos Goytacazes, RJ, Brazil.

${ }^{3} \mathrm{PhD}$, Associate Professor, Escola de Enfermagem, Universidade de São Paulo, São Paulo, SP, Brazil.
}

Corresponding Author:

Daisy Maria Rizatto Tronchin

Universidade de São Paulo. Escola de Enfermagem

Av. Dr. Enéas de Carvalho Aguiar, 419

Bairro: Cerqueira César

CEP: 05403-000, São Paulo, SP, Brasil

E-mail: daisyrt@usp.br
Copyright () 2014 Revista Latino-Americana de Enfermagem This is an Open Access article distributed under the terms of the Creative Commons Attribution Non-Commercial License (CC BY-NC).

This license lets others distribute, remix, tweak, and build upon your work non-commercially, and although their new works must also acknowledge you and be non-commercial, they don't have to license their derivative works on the same terms. 


\section{Introduction}

In the majority of health institutions, the constant search for quality, through the use of best practice and the offer of the best service so as to meet the service users' needs and expectations, is a reality. It is no different in relation to the hemodialysis service, as the treatment is complex, with specific activities, requiring an appropriate structure and professionals who are trained to provide safe assistential practice; these needs, if not respected, can cause irreversible damage to the service user.

Quality in health care is the obtaining of greater benefits with low risks to the user. In their turn, the benefits are defined in terms of achievability, in line with the resources available and the existing social values. This is not an abstract attribute; rather, it is constructed by the assistential evaluation; according to Donabedian's evaluative model, it is proposed that this should be undertaken through the analysis of the structure, the work processes and the results ${ }^{(1-3)}$.

Quality includes the unceasing search for identification of shortcomings in the procedures and practices which organize the actions, leading to improvement in the processes and results, considering the conformities established by the regulatory bodies, and the satisfaction of the service users ${ }^{(4-5)}$.

The maintenance of adequate standards of the $\mathrm{Hd}$ in patients with kidney disease directly depends on efficient vascular access (VA), complications of which are highly represented among the morbidities in this group. Considering the importance of VA, moreover, it is worth emphasizing that the therapy's efficacy is very closely related to its appropriate implanting, handling and monitoring, which are reflected in the quality of the dialysis and, consequently, in the patient's well-being and survival(6-7).

Of the different health evaluation instruments, indicators are increasingly standing out, above all those constructed, validated and applied for analyzing a given phenomenon or situation.

In analyzing the advantages of using the processes' quality indicators, data from the literature shows that these provide concrete elements of the context, addressing the issue of the results' viability ${ }^{(3)}$. There is consensus that the services must select indicators which reflect practices or areas which need decisions to be made with as little uncertainty as possible. In this way, the information instrumentalizes the analysis of the institutional processes with rationality and criticality ${ }^{(8)}$.
Bearing in mind the above, and given the importance of quality linked to safe assistential practice, with a view to the continuous improvement of the $\mathrm{Hd}$ services (above all in the appropriate management of these services' users' VA) and, furthermore, taking into account the gap existing in the evaluation of this practice, through the use of tools for measuring quality, it was considered relevant to develop the present study, which aimed to evaluate the conformity of the assistential practice of maintenance of the temporary double-lumen catheter for hemodialysis, through the use of the process indicator, in the University Hospital of the University of São Paulo.

\section{Method}

This study has a quantitative approach and is exploratory-descriptive and observational. It was undertaken in the Hemodialysis Unit of the University Hospital of the University of São Paulo (HU-USP).

Data collection occurred in the period March November 2011, in the morning and afternoon shifts, through structured observation. This technique involves the use of formal instruments and protocols which guide what is to be observed, how long the technique should take, and how the data should be recorded, with the aim of documenting specific behaviors, actions and events ${ }^{(9)}$. The researcher used two forms: the first, based on the Operational Manual of the MTDLCH Indicator(7), used for assessing the conformity of the assistential practice, containing data referring to the number of the observation, the data, the shift, the 13 components to be evaluated and the result of the evaluation; and the second, to record the data for characterizing the service users by sex, age, and the first three diagnoses on admission to the Hd program.

The sample was made up of 155 observation opportunities, each one made up of 13 specific components, corresponding to the evaluation of 2,015 components of the practice of maintaining the temporary double-lumen catheter (TDLC) for $\mathrm{Hd}$, undertaken by the health professionals. The sampling, which was nonprobabilistic and of convenience, was undertaken over eight months, representing the opportunities evaluated in the $\mathrm{Hd}$ unit of the HU-USP.

It was considered that the conformity of the activities or processes consisted of meeting a specific standard which was able to define the desired quality in a way that did not compromise the coherence and what was called for by the service, observed during the evaluation $(2,10)$. 
The patients with $\mathrm{Hd}$ catheters were not approached during the study, and the data collection did not entail any alteration of the practice habitually carried out by the health professionals. The research project was submitted to the above-mentioned hospital's Nursing Department and Research Ethics Committee and was approved (Protocol no 1.080/10 - SISNEP CAAE 0107.0.198.196-10). The health professionals working in the unit - who were, therefore, those who could be observed - were consulted regarding their availability to participate in the research and were informed about the study's objectives and the confidentiality of their identities and roles. Thus, all the professionals in the health team participated in the study, signing the
Terms of Free and Informed Consent (TFIC) which were provided in two copies, one remaining with the respondent and one with the researcher, in line with Resolution no 196/96.

The data obtained was organized in an electronic spreadsheet in the Microsoft Excel ${ }^{\circledR}$ program, following which it was treated through statistical analysis using the Statistical Package for the Social Sciences (SPSS ${ }^{\circledR}$ ) software. The treatment of the data was effected through descriptive statistics.

For the calculation of the indicator rates, the researchers used the formulas, for general conformity and for each component evaluated, recommended in the Operational Manual for the indicator referred to ${ }^{(7)}$.

$$
\text { General indicator }=\frac{\begin{array}{c}
\text { Number of persons with TDLC with all } \\
\text { the items of maintenance in conformity }
\end{array}}{\text { Total of persons with TDLC evaluated }} \times 100
$$

$\begin{gathered}\text { Indicator, by } \\ \text { component/variable }\end{gathered}=\frac{\begin{array}{c}\text { Number of persons with TDLC handled after } \\ \text { hygienization of the professionals' hands }\end{array}}{\text { Total of persons with TDLC evaluated }} \times 100$

The result of the above formulae is presented in the form of a spidergraph, as this allows one to examine the relationship potential between all the variables analyzed, simultaneously; it is considered a visual information tool for the performance of a series of indicators and permits rapid visualization, as well as facility of comprehension regarding the performance of the object evaluated(11-12).

\section{Results}

In the period of the study, 155 opportunities for observation of the assistential practice were evaluated. Each opportunity was made up of 13 specific components, totalling 2,015 observations evaluated. The researchers observed the Hd sessions of 41 service users, among whom the access was the TDLC, and these were characterized in terms of the variables sex, age, and diagnosis on admission to the Hd unit.

In relation to sex, there was a predominance of men - 31 (75.6\%). In regard to age, the mean was 55 years old ( $s d \pm 16.5)$, varying from 20 to 84 years old, the median age being 57 . When the mean ages were compared between the sexes, there was no statisticallysignificant difference ( $p=0.455$, Student t test). Systemic Arterial Hypertension (SAH) was diagnosed in $56.6 \%$ of the patients, followed by Acute Chronic Kidney Disease (39.5\%) and Diabetes Mellitus (DM) (36.8\%).

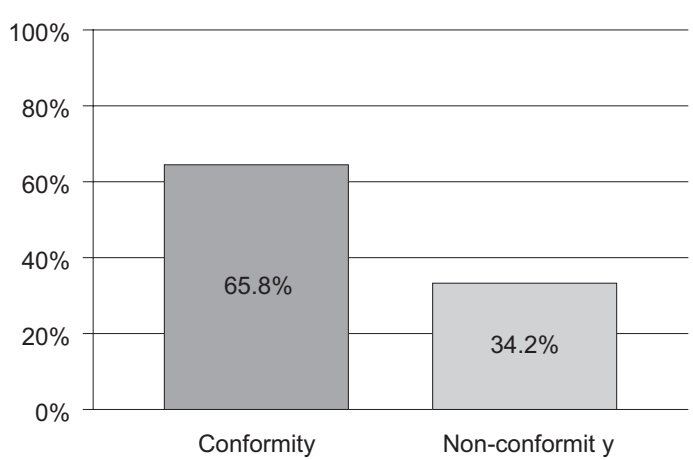

Figure 1 - Distribution of conformity and non-conformity of the practice of maintenance of the TDLC, HU-USP, São Paulo, state of São Paulo (SP), Brazil, 2011

By analyzing Figure 1, it may be observed that the percentage of general conformity of the assistential practice of maintenance of the TDLC for Hd corresponds to $65.8 \%$.

According to the results presented in the table above, one can perceive that of the 13 specific components evaluated, $9(69.2 \%)$ achieved the maximum percentage of conformity $(100 \%)$, viz: handling of the TDLC with sterile gloves; use of a mask by the health professional when disconnecting the $\mathrm{Hd}$; inspection of the insertion of the TDLC during the changing of the dressing; use of alcoholic chlorhexidine $0.5 \%$ when changing the 
dressing; changing the dressing prior to the Hd session; covering of the dressing with sterile gauze each session or with a transparent film every 7 days, or when necessary; hygienization of the connectors with alcoholic chlorhexidine at $0.5 \%$; filling of the tubing of the TDLC, after the session, with $10 \mathrm{ml}$ of saline solution $0.9 \%$ in each tube; and filling of the tubing of the TDLC after the infusion of saline solution $0.9 \%$, with heparin solution.

Table 1 - Distribution of conformity and non-conformity of each component/variable of the practice of maintenance of the TDLC, HU-USP, São Paulo, SP, Brazil, 2011

\begin{tabular}{|c|c|c|c|c|c|c|}
\hline \multirow{2}{*}{ Components/variables } & \multicolumn{2}{|c|}{ Conformity } & \multicolumn{2}{|c|}{ Non-conformity } & \multicolumn{2}{|c|}{ Total } \\
\hline & $\mathbf{n}$ & $\%$ & $\mathbf{n}$ & $\%$ & $\mathbf{N}$ & $\%$ \\
\hline Hand hygienization & 130 & 83.9 & 25 & 16.1 & 155 & 100.0 \\
\hline Handling with sterile gloves & 155 & 100.0 & 0 & 0.0 & 155 & 100.0 \\
\hline Use of mask by professional in the connecting & 154 & 99.4 & 1 & 0.6 & 155 & 100.0 \\
\hline Use of mask by professional in the disconnecting & 155 & 100.0 & 0 & 0.0 & 155 & 100.0 \\
\hline Use of mask by patient in the connecting & 143 & 92.3 & 12 & 7.7 & 155 & 100.0 \\
\hline Use of mask by patient in the disconnecting & 130 & 83.9 & 25 & 16.1 & 155 & 100.0 \\
\hline Inspection of the insertion of the TDLC & 155 & 100.0 & 0 & 0.0 & 155 & 100.0 \\
\hline Use of alcoholic chlorhexidine $0.5 \%$ & 155 & 100.0 & 0 & 0.0 & 155 & 100.0 \\
\hline Changing the dressing & 155 & 100.0 & 0 & 0.0 & 155 & 100.0 \\
\hline Dressing with gauze or transparent film & 155 & 100.0 & 0 & 0.0 & 155 & 100.0 \\
\hline Hygienization of the connectors & 155 & 100.0 & 0 & 0.0 & 155 & 100.0 \\
\hline Filling of the tubing with saline solution $0.9 \%$ & 155 & 100.0 & 0 & 0.0 & 155 & 100.0 \\
\hline Filling of the tubing with heparin & 155 & 100.0 & 0 & 0.0 & 155 & 100.0 \\
\hline
\end{tabular}

Based on the data presented in Table 1, it may be observed that regarding hand hygienization, in spite of the predominance of conformity, a considerable number of opportunities were found not to conform, showing the frailty of the adherence to the practice.

The rates of conformity of the components of the practice of maintenance of the TDLC for Hd are grouped below in the form of a spidergraph.

The management of the quality of the data, and the visualization of the results, must also be valued and incorporated by the professionals who work with indicators.

Figure 2 evidences that in adopting the MCTDLH indicator as a tool for measuring the quality of the assistential practice, other aspects may be required, such as the construction of a culture of evaluation, guided by an educational paradigm, as much for the health professionals as for the service users, which calls for an ongoing focus on the improvement of the service provided.

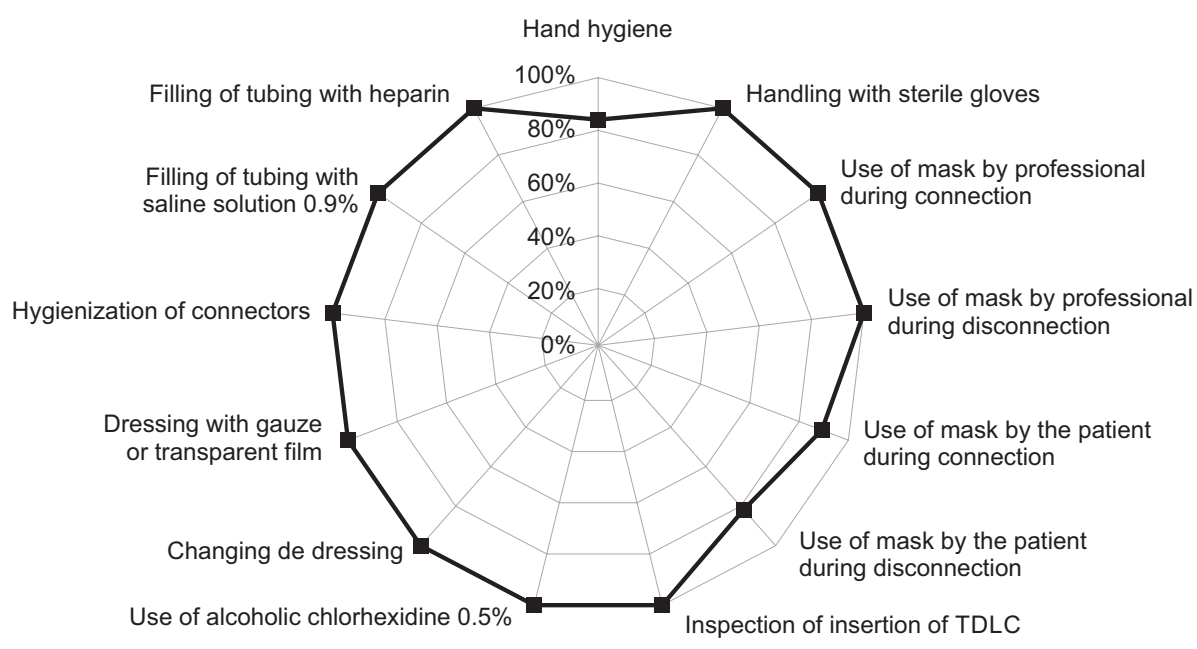

Figure 2 - Distribution of the conformity by component of the assistential practice evaluated, HU-USP, São Paulo, SP, Brazil, 2011 


\section{Discussion}

155 observation opportunities referent to the assistential practice were evaluated, in order to compose the MTDLCH indicator. Regarding the time of day that the opportunities took place, 126 (81.3\%) were during the morning shift and 29 (18.7\%) during the afternoon shift, totalling 1,638 evaluations of the specific components in the morning and 377 in the afternoon. The variation in the frequency between the shifts resulted from the patients' requirements, indicating that in the HU/USP, the majority of the $\mathrm{Hd}$ sessions for persons with TDLC occur in the mornings.

In relation to the characteristics of persons with the catheter, this study's findings were similar to those found in the Brazilian literature ${ }^{(13)}$, regarding the variables of sex and age; and regarding the predominance of SAH and DM as the main diagnoses ${ }^{(14-15)}$.

The epidemiological profile of the patients undergoing Renal Replacement Therapy (RRT) in Brazil in the period 2000 - 2004 showed that most (57\%) of those who started RRT by Hd were men, with a mean age of 53 years old ( $s d \pm 17$ ) and a median age of 54 years old $^{(16)}$. The results of other studies held with patients receiving the same therapy also showed a predominance of men ${ }^{(17-19)}$.

In Brazil, between 2000 and 2004, 90,356 patients started dialysis, with the Hd modality predominating(16-17). In 2010, it is calculated that the number of patients admitted to dialysis programs was 18,972 , with the incidence rate estimated at 9.5 patients per million of the population(14).

In this context, the maintenance of the TDLC for $\mathrm{Hd}$ is held as a practice of fundamental importance, undertaken predominantly by the nursing team, and depending on the professional's technical competence and dexterity, as well as on the interaction and communication of this team with the multiprofessional team and the service user so as to ensure the quality, the safety of the process, and the success of the therapy.

It may be observed in the present study's results that the percentage of general conformity in the assistential practice of maintenance of the temporary catheter for $\mathrm{Hd}$ was $65.8 \%$.

In taking into account the data found in the literature, one may perceive that there has been an increase in the number of studies evaluating assistential practices; as well as great variation between them in the results of the conformity rates.
However, the best results expected are in percentages $\geq$ to $80 \%{ }^{(15)}$. In the comparison of this study with the best general conformity rates cited above, a difference of $14.2 \%$ was observed, denoting weaknesses in the process which may be the object of actions by the continuing education services, the object of revision of the assistential protocol, and the object of increasing participation by the service users in the health care.

The central venous catheter (CVC) is a sterile device, which requires specific care in its handling, as a result of which its handling must be carried out respecting the principles of the sterile technique; in this study, the component which corresponded to handling with aseptic technique was one of those which obtained $100 \%$ conformity.

In addition to this, it is recorded in the Brazilian and international literature that, following the same advice as given for the CVC dressing, that of the TDLC for $\mathrm{Hd}$ must obey the precepts of aseptic technique, using sterile gauze for each session, or transparent film, every seven days, aiming to cover the place of insertion, also applying chlorhexidine or another antiseptic solution of the professional's choice ${ }^{(20-21)}$.

Studies ${ }^{(7,22)}$ mention that changing the dressing must be undertaken prior to beginning the hemodialysis session, and recommend the professional's attention to the inspection of the catheter's exit site, these procedures being considered in the present investigation's evaluation opportunities, with a conformity rate of $100 \%$ for both practices, in addition to the use of sterile gauze or transparent film. Furthermore, in the applying of the dressing, both in the connection and disconnection of the catheter, the use of a surgical mask or face protection is recommended for the professional and patient alike, thus reducing the risks of contamination ${ }^{(21)}$.

In relation to the use of the mask in undertaking the practice evaluated, the results showed that its use by the professional in the connecting and disconnecting of the Hd was complied with in the majority of the evaluation opportunities, being $99.4 \%$ in conformity in the connection, and $100 \%$ in the disconnection.

On comparing the above-mentioned findings with those corresponding to the use of the mask by the patient in the connection and disconnection of the $\mathrm{Hd}$ a lower conformity rate was evidenced in the latter, $92.3 \%$ of the opportunities being in conformity in the connection of the $\mathrm{Hd}$, and $83.9 \%$ in the disconnection, which indicates the need for attention on the part of the health professionals, given that this is a conduct 
recommended in the literature ${ }^{(7)}$. Nevertheless, it is sometimes neglected, compromising the prevention and control of healthcare-associated infections.

In this study, it was observed that in the component of hand hygienization, in spite of the predominance of conformity - 130 (83.9\%) - a considerable number of opportunities - 25 (16.1\%) - were not in conformity, demonstrating the weakness in adherence to the practice. Conformity was considered to be present only when the professional undertook the practice of hand hygienization before and after the connection and disconnection of the $\mathrm{Hd}$.

In the dialysis services, innumerable patients receive $\mathrm{Hd}$ treatment at the same time, in the same environment, which favors the dissemination of microorganisms by direct or indirect contact via devices, equipment, surfaces or the health professionals' hands, which evidences the need for undertaking hand hygienization before and after patient contact ${ }^{(21)}$.

In a multicentric investigation carried out in nine Spanish Hd units, where the objective was to identify the factors which affect adherence to the practice of hand hygienization in Hd units, it was ascertained that in 1,902 opportunities, there was adherence of $35.6 \%$ to the practice after patient contact, and a mere $13.8 \%$ prior to patient contact(23).

The issue described above is recurrent in the health services, and is treated as priority by the programs and initiatives which focus on safety in patient care, such as the World Alliance for Patient Safety, a WHO initiative, launched in 2005, which has dedicated efforts to elaborating guidelines and strategies for the implantation of measures, including the adherence to the practice of hand hygienization, and, more recently, in Brazil, by the Ministry of Health's Ordinance no 529/2013, which instituted the National Program for Patient Safety(24).

Encouraging this practice is one of the nine solutions for patient safety launched in 2007 in the Nine Patient Safety Solutions program, considered the primary preventive measure to avoid harm to patients ${ }^{(25)}$.

In the light of the above, the specific indicator of the practice of hand hygienization has been negatively influencing the assistential processes' general rates of conformity, impairing the quality of the services and the safety of the patients.

Changing health professionals' behavior is a big challenge for the government, institutions, managers and other professionals who dedicate efforts in this direction, as it is a fundamental condition for the adherence to the recommendations and protocols directed at improving health care practices, with a view to the safety of patients and professionals in the undertaking of the procedures.

\section{Conclusion}

In using and assessing the indicator of the process of Maintenance of the Temporary Double-Lumen Catheter for $\mathrm{Hd}$, it was possible to learn that this constitutes a significant tool in the monitoring of the quality of the assistential processes undertaken in the ambit of the $\mathrm{Hd}$ unit in the HU-USP.

In the light of the findings, the authors observe that the general rate of conformity was above $80 \%$, a percentage indicated as the conformity expected in some studies similarly conducted to evaluate assistential practices. However, most of the 13 components of the indicator achieved $100 \%$ conformity.

In relation to the non-conformities, the hand hygienization by the professional and the use of the mask by the patient in the disconnection of the Hd predominated, both presenting the same rate in the opportunities evaluated. In this regard, the importance of the involvement of the managers and health professionals in the reviewing of these rates is ratified, exploring other elements which may influence the process, such as structural, material and behavioral issues.

In this perspective, the authors consider that the undertaking of studies with similar designs can provide results capable of promoting benchmarking among the Hd services, and produce consistent scientific evidence for supporting managerial and assistential practice, directing professionals' attention towards the importance of conformity in the carrying-out of the processes, supporting continuous improvements in the care given. Equally, they would allow consensus and the establishment of acceptable conformity rates, bearing in mind the complexity of the practices in hemodialytic therapy, and their repercussions on the safety and health of the individuals.

\section{References}

1. Donabedian A. The quality of care. How can it be assessed? J Am Med Assoc. 1988;260(12):1743-8.

2. Donabedian A. The seven pillars of quality. Arch Pathol Lab Med. 1990; 114(11):1115-8.

3. Donabedian A. The role of outcomes in quality assessment and assurance. QRB Qual Rev Bull. 1992;18(11):356-60. 
4. D'Innocenzo M, Adami NP, Cunha ICKO. O movimento pela qualidade nos serviços de saúde e enfermagem. Rev Bras Enferm. 2006;59(1):84-8.

5. Feldman LB, Cunha ICKO. Identification of result evaluation criteria for nursing service in hospital accreditation programs. Rev. Latino-Am. Enfermagem. 2006;14(4):540-5.

6. Mangini C, Camargo LFA, coordenadores. Prevenção de infecção relacionada à diálise. São Paulo: APECIH - Associação Paulista de Estudos e Controle de Infecção Hospitalar; 2005.

7. Nicole AG, Tronchin DMR. Indicadores para avaliação do acesso vascular de usuários em hemodiálise. Rev Esc Enferm USP. 2011;45(1):206-14.

8. Bohomol E. Padrões para avaliação da qualidade da assistência de enfermagem. In: D'Innocenzo M, Feldman LB, Fazenda NRR, Helito RAB, Ruthes RM. Indicadores, auditorias, certificações. Ferramentas de qualidade para gestão em saúde. São Paulo: Martinari; 2006. p. 71-86. 9. Polit DF, Beck CT, Hungler BP. Fundamentos de Pesquisa em Enfermagem: métodos, avaliação e utilização. 5a ed. Porto Alegre: Artmed; 2004.

10. Organização Nacional de Acreditação - Manual Brasileiro de Acreditação. 6a ed. Brasília; 2010.

11. Hinchliffe S. Implementing quality care indicators and presenting results to engage frontline staff. Nurs Times. 2009;105(25):12-4.

12. Sullivann J, Brust P, Wren PJ, Rich V. A staffingeffectiveness methodology for analyzing human resource and clinical/service screening indicator date. Jt Comm J Qual Saf. 2004;30(6):322-30.

13. Ferreira $V$, Andrade $D$, Santos $C B$, Moysés Neto M. Infecção em pacientes com cateter temporário duplo-lúmen para hemodiálise. Rev Panam Infectol. $2005 ; 7(2): 16-21$.

14. Sesso RC, Lopes AA, Thomé FS, Lugon JR, Santos DR. Relatório do censo brasileiro de diálise de 2010. J Bras Nefrol. 2011;33(4):442-7.

15. Rembold SM, Santos DLS, Vieira GB, Barros MS, Lugon JR. Perfil do doente renal crônico no ambulatório multidisciplinar de um hospital universitário. Acta Paul Enferm. 2009;22(n. esp):501-4.

16. Cherchiglia ML, Machado EL, Szuter DAC, Andrade EIG, Acúrcio FA, Caiaffa WT, et al. Perfil epidemiológico dos pacientes em terapia renal substitutiva no Brasil, 2000-2004. Rev Saúde Pública. 2010;44(4):639-49.

17. Peres $L A B$, Biela $R$, Herrmann M, Matsuo, Kyung Ann $\mathrm{H}$, Camargo MTA, Rohde NRS, Uscocovich VSM. Estudo epidemiológico da doença renal crônica terminal no Oeste do Paraná: uma experiência de
878 casos atendidos em 25 anos. J Bras Nefrol. 2010;32(1):51-6.

18. Bertolin DC, Pace AE, Kusomota $L$, Haas V. Associação entre os modos de enfrentamento e as variáveis sociodemográficas de pessoas em hemodiálise crônica. Rev Esc Enferm USP. 2011;45(5):1070-6.

19. Cesarino CB, Ribeiro RCHM, Lima ICPC, Bertolin DC, Ribeiro DF, Rodrigues AMS. Avaliação do grau de satisfação de pacientes renais crônicos em hemodiálise. Acta Paul Enferm. 2009;22(n. esp):519-23.

20. Barros LFNM, Arênas VG, Bettencourt ARC, Diccini S, Fram DS, Belasco AGS, et al. Avaliação do tipo de curativo utilizado em cateter venoso central para hemodiálise. Acta Paul Enferm. 2009;22(n. esp):481-6. 21. O'Grady NP, Alexander M, Burns LA, Dellinger EP, Garland J, Heard SO, et al. Healthcare Infection Control Practices Advisory Committee (HICPAC). Guidelines for the prevention of intravascular catheter-related infections, 2011. Atlanta: Centers for Disease Control and Prevention (CDC); 2011.83 p.

22. Sociedad Española de Nefrologia. Guías de accesso vascular em hemodiálisis. Madrid; 2004.

23. Fram DS, Taminato M, Ferreira D, Neves L, Belasco AGS, Barbosa DA. Prevenção de infecções de corrente sanguínea relacionadas a cateter em pacientes em hemodiálise. Acta Paul Enferm. 2009;22(n. esp):564-8.

24. Brasil. Ministério da Saúde. Portaria GM n. 529, de $1^{\circ}$ de abril de 2013. Institui o Programa Nacional de Segurança do Paciente (PNSP) [legislação na internet]. Brasília; 2013. [acesso 11 jul 2013]. Disponível em: http://bvsms.saude.gov.br/bvs/saudelegis/gm/2013/ prt0529_01_04_2013.html

25. Arenas MD, Sánchez-Payá J, Barril G, GarciaValdecasas J, Gorriz JL, Soriano A, et al. A multicentric survey of the practice of hand hygiene in haemodialysis units: factors affecting compliance. Nephrol Dial Transplant. 2005;20:1164-71.
Received: Oct. $16^{\text {th }} 2012$ Accepted: July 30 2013 